\title{
A PLURALIDADE INSTITUCIONAL COMO FERRAMENTA POLÍTICA NA AMÉRICA DO SUL: SOBREPOSIÇÕES ORGANIZACIONAIS E FRAGMENTAÇÃO REGIONAL
}

\author{
Karina Lilia Pasquariello Mariano² \\ Clarissa Correa Neto Ribeiro ${ }^{3}$
}

\begin{abstract}
Este artigo analisa os significados da pluralidade de organizações regionais na América do Sul para a construção de um projeto de região, com o objetivo de refletir acerca das implicações do chamado overlapping regionalism, ou regionalismo sobreposto, demonstrando suas contribuições para as crises institucionais, a estagnação e o colapso de alguns processos, atentando para a possibilidade de desintegração, ou fragmentação. 0 pressuposto aqui apresentado é de que a profusão de processos de regionalismo na América do Sul, e sua consequente sobreposição de atuações e afiliações entre os blocos, especialmente no que diz respeito às experiências das primeiras décadas do século XXI, tenderia a se perpetuar, uma vez que, considerados os processos, atores e agendas, as sobreposições serviriam como ferramenta aos interesses políticos dos governos da região, que podem priorizar suas atuações entre os projetos, de acordo com as estratégias daquele determinado momento, evitando o aprofundamento e os consequentes constrangimentos de um projeto integrado. Buscamos demonstrar esse aspecto a partir da ótica dos principais processos de regionalismo da América do Sul, como Mercado Comum do Sul (Mercosul), União de Nações Sul-Americanas (Unasul), Comunidade Andina (CAN) e Aliança do Pacífico, e de seus desdobramentos, a partir das implicações das sobreposições organizacionais, tendo em vista o contexto de crise atual.
\end{abstract}

Palavras-chave: regionalismo; América do Sul; blocos regionais; sobreposição institucional; fragmentação.

\section{INSTITUTIONAL PLURALITY AS A POLITICAL TOOL IN SOUTH AMERICA: OVERLAPPING ORGANIZATIONS AND REGIONAL FRAGMENTATION}

This article analyzes the meanings of the plurality of regional organizations in South America for the construction of a regional project, with the objective of reflecting on the implications of the so-called overlapping regionalism, demonstrating their contributions to institutional crises, stagnation and collapse of some processes, underscoring the possibility of disintegration, or fragmentation. The assumption presented here is that the profusion of regionalism processes in South America, and their consequent overlap of actions and affiliations between the blocs, especially with regard to the experiences of the first decades of the 21st century, would tend to perpetuate itself, considering the processes, actors

\footnotetext{
1. Uma versão preliminar deste trabalho foi apresentada à Associação Nacional de Pós-Graduação e Pesquisa em Ciências Sociais (Anpocs) e a International Studies Association (ISA) em 2016 e 2017, tendo sido revisada, reescrita e atualizada com mudanças significativas para esta publicação.

2. Professora associada da Universidade Estadual Paulista Júlio de Mesquita Filho (Unesp/Faculdade de Ciências e Letras - FCLar); e professora no Programa de Pós-graduação em Relações Internacionais San Tiago Dantas - Unesp, Universidade Estadual de Campinas (Unicamp) e Pontifícia Universidade Católica de São Paulo (PUC-SP). Coordena 0 Grupo de Estudos Interdisciplinares em Cultura e Desenvolvimento (GEICD) e o Observatório de Regionalismo (ODR) que integram a Rede de Pesquisa em Política Externa e Regionalismo (Repri).E-mail: <karinapmariano@gmail.com>. Orcid: <https://orcid.org/0000-0002-4559-918X>.

3. Doutora e mestre em Relações Internacionais pelo Programa de Pós-Graduação em Relações Internacionais San Tiago Dantas (Unesp/Unicamp/PUC-SP). É membro da Repri e do ODR. E-mail: <clarissacnribeiro@gmail.com>. Orcid: <https://orcid.org/0000-0002-7653-7635>.
} 
and agendas, since the overlaps would serve as a tool to the political interests of the governments of the region, which can then prioritize their actions between projects, according to the strategies of that moment, avoiding the deepening and the consequent constraints of an integrated project. We demonstrate this aspect from the perspective of the main processes of regionalism in South America, such as Mercosur, Unasur, CAN and the Pacific Alliance, and their developments, based on the implications of organizational overlaps, in view of the current crisis context.

Keywords: regionalism; South America; regional blocs; overlapping institutions; fragmentation.

\title{
LA PLURALIDAD INSTITUCIONAL COMO HERRAMIENTA POLÍTICA EN AMÉRICA DEL SUR: SUPERPOSICIONES ORGANIZACIONALES Y FRAGMENTACIÓN REGIONAL
}

\begin{abstract}
Este artículo analiza los significados de la pluralidad de organizaciones regionales en América del Sur para la construcción de un proyecto regional, con el objetivo de reflexionar sobre las implicaciones del llamado overlapping regionalism, o regionalismo superpuesto, de manera a demostrar sus contribuciones a las crisis institucionales, el estancamiento y el colapso de algunos procesos, prestando atención a la posibilidad de desintegración o fragmentación. El supuesto presentado aquí es que la profusión de los procesos de regionalismo en América del Sur y su consecuente superposición de acciones y afiliaciones entre los bloques, especialmente con respecto a las experiencias de las primeras décadas del siglo XXI, tendería a perpetuarse considerando los procesos, actores y las agendas, ya que las superposiciones servirían como herramienta para los intereses políticos de los gobiernos de la región, que pueden priorizar sus acciones entre los proyectos, de acuerdo con las estrategias de ese momento determinado, evitando la profundización y las consiguientes limitaciones de un proyecto integrado. Buscamos demostrar este aspecto desde la perspectiva de los principales procesos de regionalismo en América del Sur, como el Mercado Común del Sur (Mercosur), Unión de Naciones Suramericanas (Unasur), Comunidad Andina (CAN) y la Alianza del Pacífico, y sus desarrollos, a partir de las implicaciones de las superposiciones organizacionales, en vista del contexto actual de crisis.
\end{abstract}

Palabras clave: regionalismo; América del Sur; bloques regionales; solapamiento institucional; fragmentación.

JEL: F55.

DOl: http://dx.doi.org/10.38116/rtm23art2

Data de envio do artigo: 17/6/2020; Data de aceite: 11/8/2020.

\section{INTRODUÇÃO}

O início do século XXI trouxe consigo uma efervescência de iniciativas regionais na América do Sul que levaram à conformação de um cenário institucional complexo do chamado overlapping regionalism, ou regionalismo sobreposto, que ocorre quando os países de uma região participam simultaneamente de mais de um bloco regional, sobrepondo seus mandatos e afiliações. Nos últimos anos, mesmo com a crise regional, tal complexidade apenas se acentuou, já que a proposta de novos projetos também veio acompanhada do desmonte de outros. Portanto, as consequências da proliferação institucional e seu uso na regiáo são o objeto deste artigo, que discute as implicaçóes dessa multiplicidade de blocos de cooperação 
e integração sul-americanos com o intuito de analisar os desdobramentos da multiplicidade de organizaçôes, com especial atenção para sua influência no processo de (des)integração ou fragmentaçấo da região.

Ainda que inicialmente os governos e a literatura especializada argumentassem que a existência de diversas instituiçóes regionais poderia se mostrar complementar, náo implicando em conflitos de interesse, uma vez que os objetivos dos processos seriam dotados de diferentes orientaçóes, a análise de algumas experiências de regionalismo indica que essa convivência pode não ter sido tão bem articulada quanto se afirmou, devido aos significados aportados pela sobreposiçāo institucional. Portanto, embora o fenômeno possa ter representado, durante a primeira década do século XXI, um cenário de potencial complementaridade, havia subjacente uma perspectiva competitiva que contribuiu, ao longo do tempo, para um uso pragmático das diferentes camadas regionais e a consequente erosão do sistema.

A segmentação dos processos de integração regional e sua consequente sobreposição não é uma característica exclusiva da América Latina, sendo encontrada em outras regióes do mundo, inclusive na Europa. A mera multiplicidade de processos regionais coexistentes não é um problema em si, uma vez que, conforme argumentado, pode existir uma articulação capaz de produzir complementaridades entre eles, criando uma espécie de sinergia positiva (Nolte, 2014). Até mesmo a razão da existência de múltiplas organizaçôes na América do Sul poderia ser inicialmente explicada em razão de seu potencial positivo, se entendida como um momento de efervescência política e social que valorizou o relacionamento regional, traduzido na criação de novas instituiçóes (Riggirozzi e Tussie, 2012).

No entanto, essa mesma pluralidade poderia também sinalizar uma incapacidade administrativa na articulação de diferentes estratégias de inserção regional, ou no estabelecimento de um plano de longo prazo, ou, ainda, a existência de um conflito de interesses entre a promoção de processos mais complexos e a resistência em estabelecer estruturas administrativas regionais com autonomia para articular essas açôes. No caso sul-americano, os indícios apontam justamente a ausência de uma articulação bem-sucedida. Portanto, os efeitos dela derivados se mostram um impasse na consecução dos objetivos primários de uma integração, uma vez que a grande variedade de interesses e países envolvidos dificulta a convergência dos vizinhos em torno de um projeto comum, o que contribui para a manutençấo das sobreposiçōes e fragmenta a região.

É interessante apontar que a sobreposição na América do Sul, ou sua intensificação, ocorre justamente no momento em que, aparentemente, há uma preponderância nos governos de uma perspectiva cooperativa - ou até mesmo integracionista -, e uma menor influência de potências exteriores. Durante a 
primeira década do século XXI, preponderou nos discursos dos governos da região a preocupação com uma inserção coletiva e autônoma no sistema internacional, indicando uma disposiçấo em torno de um projeto conjunto, mas certamente não único.

Consideramos que a multiplicidade de projetos decorrentes desse contexto que trabalhamos aqui sob a conceituação de overlapping ou regionalismo sobreposto - provocou importantes desdobramentos em projetos anteriores, como no Mercado Comum do Sul (Mercosul) ou na Comunidade Andina (CAN), assim como nas iniciativas de regionalismo que surgiram a partir desse contexto, como foi o caso da União das Naçóes Sul-Americanas (Unasul).

Este artigo analisa os significados da pluralidade de instituiçóes para a construçáo de um projeto regional. Tendo em vista os diferentes contextos em que surgiram esses processos e como se relacionaram entre si durante as duas primeiras décadas do século XXI, que englobam tanto um período de alta como também de queda do impulso regionalista, é possível projetar uma análise conjuntural sobre a percepção em relação aos diferentes interesses para a integração.

O pressuposto deste artigo é que a profusão de processos de regionalismo na América do Sul, e a consequente sobreposição de atuações e afiliaçóes entre os blocos, no que diz respeito aos processos, interesses e agendas, se perpetua e tende à continuidade. Isso ocorre porque as sobreposiçôes serviriam aos interesses políticos dos governos da regiáo, que podem priorizar suas atuaçóes entre os projetos, de acordo com as estratégias daquele determinado momento, evitando o aprofundamento e os consequentes constrangimentos de um projeto integrado. Buscamos demonstrar esse aspecto a partir da ótica dos principais processos de regionalismo da América do Sul e de seus desdobramentos, refletindo sobre as implicaçóes dessa sobreposição e sua extensão para o contexto atual. Portanto, o objetivo desta análise é refletir acerca das implicaçóes do regionalismo sobreposto, mostrando como este contribuiu para o colapso e crises de alguns processos, para a estagnação de outros ou mesmo para a possibilidade de desintegração.

Esta análise divide-se em três partes. Em primeiro lugar, apresentamos a discussão teórica que reflete sobre o regionalismo sobreposto e suas potenciais consequências. Em seguida, apresentamos um panorama do regionalismo na América do Sul, considerando a proliferação de organizações regionais, suas características institucionais e os desdobramentos da crise regional das últimas duas décadas. Dedicamos a última parte deste artigo às reflexóes sobre o fenômeno do regionalismo sobreposto na América do Sul e à análise de seu papel para a fragmentação regional e a atual tendência de desintegração.

Este trabalho acomoda resultados de duas pesquisas prévias. Uma sobre as características dos atuais processos de regionalismo na América Latina, financiada 
pelo Conselho Nacional de Desenvolvimento Científico e Tecnológico (CNPq), Regionalismo na América Latina no século XXI (Mariano, 2016), e uma dissertação de mestrado que discutiu a fragmentação e a complementaridade desses processos, e contou com uma bolsa da Coordenação de Aperfeiçoamento de Pessoal de Nível Superior (Capes) para o seu desenvolvimento, Overlapping regionalism $e$ proliferação de instituiçôes na América Latina: complementaridade e fragmentação nas agendas regionais (Ribeiro, 2016).

\section{DEBATE SOBRE OS EFEITOS DA SOBREPOSIÇÃO PARA A GOVERNANÇA REGIONAL}

A complexidade do cenário regional, gerada pela convivência de múltiplos projetos sobrepostos tem sido objeto de pesquisa recorrente nos últimos anos (Riggirozzi e Tussie, 2012; Malamud e Gardini, 2012; Malamud, 2013; Weiffen, Wehner e Nolte, 2013; Gómez-Mera, 2015; Weiffen, 2017; Nolte, 2014; 2016; 2018). Pode-se dizer que os posicionamentos variaram entre um otimismo voltado para a complementaridade, cooperação e articulação de iniciativas; e um pessimismo que apontaria a descoordenação, competição e conflito entre os projetos regionais.

Devido à multiplicidade de instituiçóes, Nolte (2014) afirma que uma região passaria a ser compreendida como um complexo de governança regional, cujas interaçóes poderiam tanto gerar efeitos cooperativos como segmentados, a depender das condiçóes apresentadas. Nesse sentido, Riggirozzi e Tussie (2012) também entendem a governança regional como o resultado de diversas formas de interação, entre competição e cooperação, que transformaria a cartografia por si mesma (Riggirozzi e Tussie, 2012; Nolte, 2014). Para as autoras, o regionalismo pós-hegemônico - período que compreende o início do século XXI e a proposição e renovação dos processos regionais na América do Sul - inicialmente também contribuiria para a conformação de um complexo de governança regional, uma vez que a característica esperada era de um dinamismo que náo buscaria a amalgamação de projetos, apresentando, contudo, a tendência de florescer a partir dos resultados das interações complexas entre eles (Tussie, 2009).

Nolte (2014) buscou sistematizar os tipos de sobreposição possíveis. Consideradas as possibilidades de solapamento de atuaçáo (mandate) e de afiliação (membership) entre os blocos (Weiffen, Wehner e Nolte, 2013), elas desdobrariam e se combinariam em cenários de cooperação ou conflito. Por exemplo, se existe uma sobreposiçẫo de afiliaçôes, mas não de atuação, os blocos tenderiam a cooperar entre si, em uma situação de divisão de trabalho. Contudo, quando se constata uma sobreposição de atuação, mas não de afiliaçôes, pode-se encontrar um cenário competitivo na região - a não ser que os mecanismos sub-regionais decidam segmentar suas zonas de influência. Situaçóes com sobreposição total 
(atuação e afiliação) ou ausência de sobreposição poderiam ser conflitivas, ou cooperativas, a depender dos fatores de negociação dos países.

A competição entre instituições é mais provável se a sobreposição temática ocorrer em setores vitais ao processo, como considera Nolte (2014). As situações em que mecanismos se sobrepóem tematicamente fora de seu principal objetivo são mais tendentes a cooperar, para afirmar a combinação de associaçóes transversais com diferentes temáticas em múltiplos projetos regionais como panorama ideal. Tal composição regional contribuiria para a articulação da governança cooperativa combinando a flexibilidade dos Estados em situaçóes em que podem escolher os processos de seu interesse, com a lealdade nas demais parcerias regionais. Ainda para o autor, a presença de instituições centrais mais abrangentes poderia indicar um cenário positivo de governança, desde que tais instituiçóes articulassem os diversos foros sub-regionais e fossem capazes de construir pontes entre os diferentes mecanismos, usando a sobreposição institucional a seu favor (Nolte, 2014).

De modo a exemplificar o potencial positivo da pluralidade de instituiçóes, Nolte (2014) ainda se refere aos estudos de Hofmann e Mérand (2012), baseados na experiência europeia, os quais argumentam que o processo de negociação regional tem menos chances de falhar se os Estados tiverem a possibilidade de optar por não participar, escolhendo as políticas que mais condizem com seu interesse e configurando o conceito de um "regionalismo à la carte". Essa perspectiva estaria baseada em uma "integração de velocidades diferenciadas", e de acordos de "geometrias variadas" (Hofmann e Mérand, 2012).

No entanto, alguns posicionamentos divergem das perspectivas apresentadas. Malamud e Gardini (2012), por exemplo, afirmam que, embora nem sempre produzam um regionalismo competitivo, as sobreposições o segmentam, o que facilita a descentralização sub-regional. No caso da América Latina, a proliferação de instituiçóes muitas vezes se relaciona à construção de novos mecanismos pela exclusão de algum país, ou pela afirmação de diferença em relação aos blocos já existentes, segundo os autores.

Esse posicionamento de Malamud e Gardini (2012) destaca a sobreposição como sinônimo de exaustão do potencial de integração, o qual teria, entre suas consequências, a criação ou o aprofundamento de divisões entre os países, bem como a geração de uma desintegração hemisférica a partir do fortalecimento dos sub-regionalismos, além do aumento de atritos e tensóes.

Outra autora a refletir acerca dos efeitos causados pela complexidade do regime internacional para a governança regional é Gómez-Mera (2015). Em sua análise, não desconsidera as possibilidades de sinergia e cooperação entre as instituições, mas aponta três mecanismos a partir dos quais a proliferação de acordos internacionais sabotaria a efetividade da cooperação: fragmentação 
jurídica; uso de estratégias interinstitucionais; e a constante competição que levaria à corrosão da unidade regional.

$\mathrm{O}$ primeiro mecanismo se refere à ambiguidade normativa gerada pela sobreposição de instituições e que incrementa os problemas de cumprimento e implementaçâo nas iniciativas da América Latina. A incidência de diversas normas gera custos para os setores público e privado ao exigir maior conhecimento técnico para a realização de transaçôes e concretização de negociaçôes. Essas capacidades técnicas também possibilitam que os atores ajam por meio de diferentes regras aplicáveis, utilizando a interpretação a seu favor. Esse problema derivaria também da ausência de uma hierarquia normativa, que prejudica a resolução de conflitos e inconsistências que possam surgir entre os blocos.

O segundo mecanismo é a formulação de estratégias políticas interinstitucionais que favorecem os interesses individuais dos Estados. A proliferação de acordos disponibiliza um maior número de opçóes para os países, que podem transladar as negociaçóes de um bloco a outro, com o objetivo de se beneficiar com a influência na natureza do regime. Um exemplo seria a iniciativa brasileira durante a primeira década do século XXI de restringir o palco das negociaçóes regionais da América Latina para a América do Sul, a partir da criaçáo da Unasul. Além disso, esse mecanismo viabilizaria o forum shopping, ou a escolha do foro que mais bem beneficie os atores em caso de conflito.

Esse cenário é agravado quando a sobreposição de mecanismos de resolução de controvérsias supera a esfera regional. Assim, muitas vezes, priorizam-se mecanismos multilaterais globais (a Organização Mundial do Comércio-OMC, por exemplo) diante de conflitos, mesmo quando um julgamento já ocorreu em âmbito regional e a despeito de seu resultado, o que favorece o enfraquecimento das instituiçốes regionais.

Gómez-Mera (2015) ainda destaca que essas consequências estimulam o aprofundamento das assimetrias de poder, uma vez que os Estados mais poderosos dispóem de mais recursos para explorar as oportunidades geradas pelas sobreposiçóes e, por conseguinte, para se beneficiar nas negociações. Esse contexto também possibilitaria um posicionamento estratégico inconsistente (strategic inconsistency) diante dos diversos mecanismos regionais, de modo a criar regras contraditórias em um sistema paralelo com o objetivo de abalar a instituição original.

Por fim, o terceiro mecanismo apontado pela autora sabotaria a efetividade da cooperação: a constante competição entre Estados e regimes comprometeria a coesão e unidade regional. É a partir desse mecanismo que se pode discutir, por exemplo, a existência de uma fragmentação geográfica entre a América do Sul do Atlântico e a do Pacífico. A autora apoia-se no pensamento de Malamud e Gardini (2012), reafirmando as dificuldades aportadas pelos projetos em 
competiçấo constante para o posicionamento conjunto acerca de uma liderança regional; para o estabelecimento de qual seria a estratégia adequada para alcançar o desenvolvimento; e até mesmo para o relacionamento da regiáo com os Estados Unidos (Gómez-Mera, 2015, p. 35).

A autora não desconsidera que um cenário diverso e suas pressóes competitivas podem estimular o desenvolvimento e a inovaçấo nos projetos regionais. Porém, tampouco desconsidera que a concorrência entre os blocos pode criar ineficiências e sabotar a efetividade dos esforços conjuntos na resolução de um conflito internacional (Gómez-Mera, 2015, p. 23). Por fim, a constante competição prejudica a compreensão dos diferentes interesses do regionalismo latino-americano, o que poderia ainda contribuir para que os Estados o deixem de lado, ou optem por iniciativas individualistas ou multilaterais, em funçáo da desconfiança nas associaçốes regionais.

Dessa forma, a compreensão do regionalismo na América do Sul pressupõe considerar os desdobramentos decorrentes dessa sobreposição nos distintos processos de integração, buscando estabelecer qual a extensão de sua influência para a atual tendência de desintegração, uma vez que é expressão da fragmentação.

\section{REGIONALISMO NA AMÉRICA DO SUL}

Embora apenas duas décadas no século XXI tenham transcorrido, esses vinte anos apresentam uma dinâmica bem diversa no que se refere à dinâmica de cooperação e convergência entre os países da América do Sul. Conforme mencionamos na seção anterior, na primeira metade desse período houve uma proliferação significativa de arranjos regionais, com distintas características e agendas - embora seja possível afirmar que, de modo geral, todos apresentaram uma convergência política entre seus participantes na escolha pelo regionalismo, o que permitiu construir uma percepção de maior coesão.

Já a segunda metade apresentou inicialmente um processo de redirecionamento político que parecia indicar que a coesão existente seria mantida, mas modificando-se os interesses e agendas. No entanto, essa nova coesão não se consolidou. Diferentemente do que ocorreu durante a década de 1990, quando, apesar das diferenças, a integração regional mostrou-se central nas políticas externas dos governos, encontramos atualmente um cenário de crescente desarticulação ou desintegraçáo.

Num primeiro momento, poderíamos atribuir essa desarticulação às mudanças políticas ocorridas - principalmente com a ascensão de governos com posicionamentos de extrema direita -, e à conjuntura internacional pouco favorável tanto pelas implicaçóes produzidas pelo comportamento do governo norte-americano de Donald Trump como pelas crises constantes na União 
Europeia (crise do euro, crise de refugiados, e a desintegração do Reino Unido ao bloco europeu, o chamado Brexit), e pelo advento da própria pandemia da Covid-19. Contudo, nosso pressuposto neste artigo é que essa desarticulação na América do Sul está também diretamente relacionada aos efeitos da proliferação e sobreposição de organizaçôes regionais ocorridas na década anterior.

O que explica a atual tendência de fragmentação e desintegração não são os fatos conjunturais, mas os estruturais. Para compreender melhor esses problemas estruturais é preciso considerar as características do regionalismo na América do Sul. Em primeiro lugar, ainda que todos os processos sejam percebidos ou comumente referidos como integracionistas, nem todos podem ser classificados como processos de integração regional, mas sim como iniciativas de cooperação e regionalismo. Partindo de uma conceituaçâo clássica sobre regionalismo, devemos entender que o conceito de integração pressupóe, conforme descrito por Haas (2004, p. 16, traduçáo nossa), a transferência, por parte dos atores políticos, de "lealdades, expectativas e atividades políticas para um novo centro, cujas instituiçóes possuam ou demandem jurisdiçấo sobre os estados nacionais preexistentes".

Trata-se, portanto, de um conceito que abrange a supranacionalidade das instituiçóes regionais, ao pressupor a construção de uma nova institucionalidade para lidar com um processo de aprofundamento da interdependência entre países que vai além dos aspectos econômicos, carregando consigo um forte simbolismo, ligado a uma percepção de coesão entre seus participantes. Já o conceito de regionalismo, por sua vez, é mais elástico, estando relacionado à noção de pertencimento a um espaço geográfico ou à articulação a partir de um referencial territorial, abarcando um conjunto amplo de possibilidades de cooperação entre os atores, que náo necessariamente devem ser estatais, tampouco preocupados em intensificar a interdependência econômica entre eles (Hurrell, 1995; Börzel e Risse, 2016).

Essa distinção não é uma mera formalidade, apresentando importantes implicaçóes para as análises quando de fato os atores se dispóem a participar de uma integração, entre as quais se destacam: $i$ ) vontade política para a construção de um projeto conjunto de desenvolvimento que possa canalizar as expectativas; ii) compromisso com a constituiçấo de uma nova institucionalidade para gerir a cooperação; iii) intenção/disposição para o aprofundamento e ampliação da agenda de negociaçáo; e iv) aceitaçáo de uma perda de autonomia por parte dos países envolvidos (Haas, 2004).

Esses aspectos elencados referem-se aos comportamentos e disposiçóes esperados pelos participantes de processos de integração regional e acabam estando presentes nos discursos dos governos latino-americanos quando se referem aos 
projetos regionais nos quais participam. No entanto, há um distanciamento significativo entre essas falas políticas e as práticas implementadas de fato pelos governantes, como demonstraremos ao longo deste artigo. ${ }^{4}$

Antes de tudo está a questão da afirmação de uma vontade política para a construção de um projeto conjunto de desenvolvimento. Desde a primeira proposta de integração regional realizada por Simón Bolívar para a América Latina, está presente na sua justificação a ideia de compartilhamento de um destino comum, embora com a exclusão do Brasil (Briceño-Ruiz e Puntigliano, 2017), o que acaba pressupondo também a noção de pertencimento a uma identidade coletiva mais ampla e capaz de acomodar a pluralidade de atores presentes na regiáo. Esse tipo de discurso é recorrentemente utilizado quando há interesse por parte dos governos de defender as iniciativas integracionistas e reforçar o apoio às medidas adotadas.

Quando analisamos esse aspecto, percebe-se que esse posicionamento é mais utilizado por governos que defendem processos integracionistas menos comerciais, especialmente aqueles que proclamam uma identidade político-ideológica de centro-esquerda e consideram insatisfatória a promoção de iniciativas de integração regional com forte ênfase nas dimensóes econômica e comercial.

Os novos governos sul-americanos do início deste século assumiram um discurso de retomada do papel do Estado na promoçáo de mudanças econômicas, numa perspectiva neodesenvolvimentista e considerada progressistas, a chamada Onda Rosa: Hugo Chávez na Venezuela; Luiz Inácio Lula da Silva no Brasil; Nestor Kirchner na Argentina; Tabaré Vázquez no Uruguai; Michelle Bachelet no Chile; Evo Morales na Bolívia; Daniel Ortega na Nicarágua, Rafael Correa no Equador; e Fernando Lugo no Paraguai (Ayerbe, 2008).

Dentro desse reposicionamento ideológico, esses governos reafirmaram seu compromisso em aprofundar e ampliar a integraçáo regional, mas sob uma nova perspectiva, a defesa da promoção de uma transformação social e econômica na região - ainda mais que a conjuntura internacional apresentava-se como uma ameaça, devido às incertezas e instabilidades econômicas internacionais (Vigevani e Ramanzini Júnior, 2010; Veiga e Ríos, 2011).

Sem entrarmos numa diferenciação de estratégias e posicionamentos assumidos por esses governos, podemos afirmar que esse novo discurso deu origem a uma nova fase no regionalismo sul-americano. Isso ocorreu com o surgimento de processos voltados para o questionamento desse modelo de integração pautado na questấo comercial, chamados tanto de regionalismo pós-liberal como de

4. Conferir Mariano, Romero e Ribeiro (2015). 
pós-hegemônico (Veiga e Rios, 2007; Cienfuegos e Sanahuja, 2010; Serbin, 2011; Riggirozzi e Tussie, 2012).

As principais características atribuídas ao que seria um novo modelo de regionalismo foram: agenda integrativa de caráter desenvolvimentista (com forte preocupação pela equidade social); ampliação temática da agenda de integração, abrangendo assuntos econômicos não comerciais e temas não econômicos; incorporação e participação de grupos sociais nas estruturas da integraçấo; e maior protagonismo do Estado.

Ao mesmo tempo, nem todos os processos surgidos nesse período estão contidos nessa lógica, havendo iniciativas que buscaram reforçar os pressupostos do regionalismo aberto (Cepal, 1994). É o caso da Aliança do Pacífico, que surgiu tanto como uma alternativa a esse movimento político alinhado à centro-esquerda, como também ao processo da CAN, considerado altamente institucionalizado e com traços de supranacionalidade, mas pouco eficaz economicamente. Esse último aspecto é destacado em nossa análise por suas implicaçóes diretas para nossa argumentação. Os processos regionais atribuídos a essa nova onda ressaltaram, ao mesmo tempo, a vontade de ampliar e aprofundar a integração, compatibilizando-a com a manutenção das soberanias nacionais, o que, na prática, significava uma intensificação das lógicas intergovernamentais (Mariano e Ribeiro, 2016).

O debate entre os defensores de uma institucionalidade intergovernamental e os da supranacional tende a se concentrar sobre qual delas seria mais eficiente ou mais adequada aos processos de integração. Destaca-se que a lógica supranacional só funcionou no caso europeu e que seria resquício de outro momento e contexto, mas que náo caberia nos atuais processos integracionistas, especialmente porque representa uma tendência de burocratização que estaria em dissonância com a atual realidade.

$\mathrm{O}$ aspecto significativo da supranacionalidade não está na criação de uma instância de poder acima dos Estados ou na formaçáo de uma federaçáo de nações, como indicam alguns autores. Reside, isso sim, em um âmbito amplamente ressaltado pelos autores funcionalistas e neofuncionalistas (Mitrany, 1990; 1994; Haas, 2004): sem uma instância com autonomia em relaçáo aos governos nacionais, os processos de integração permaneceriam presos aos interesses dos governos de ocasiáo, portanto mais suscetíveis às mudanças eventuais resultantes da alternância de poder.

É justamente esse argumento neofuncionalista que se concretiza e conforma o cenário de sobreposições regionais da América do Sul. Ao diferenciarmos as duas primeiras décadas do século XXI, contrastamos o momento inicial de efervescência e relançamento de blocos regionais com a atual situação, na qual 
os foros institucionalizados anteriormente são preteridos ou desmontados, de forma a atender os interesses de novos governos, com orientação política oposta a seus antecessores. Nesse contexto é que foram criados novos mecanismos de concertação política, como o Grupo de Lima, ${ }^{5}$ em 2017, e, em seguida, o Fórum para o Progresso e Desenvolvimento da América do Sul (Prosul), em 2018, a partir da convergência de metade dos membros da Unasul.

Esse último caso é interessante porque expressa bem a lógica do regionalismo sobreposto na América do Sul. Diante de uma contexto de polarização dentro da Unasul a partir de posicionamentos ideológicos (de um lado os chamados bolivarianos; de outro, os representantes da nova direita sul-americana), a opção não foi pela concertação ou utilização dos instrumentos institucionais para se chegar a um consenso. Os governos com perfil ideológico à direita optaram não só por abandonar o processo, mas estabelecer um substituto para reafirmar sua diferenciação dos projetos de governos anteriores. É importante frisar a mudança representada pelo Prosul, pois é uma iniciativa liderada pelo governo do Chile e que não recupera nada da institucionalidade/agenda da Unasul, ainda que pretenda ser um processo de concertação política regional.

A compreensão da rápida mudança no cenário regional evidencia também a questáo da supranacionalidade no que se refere à continuidade e resistência das instituiçôes ao longo das transiçôes governamentais. Ainda assim, a simples existência de instâncias supranacionais na estrutura organizacional da integraçáo não é garantia de sua consolidação ou de seu aprofundamento, porque há também a necessidade de que possuam capacidade de implementação decisória. Nesse caso, a supranacionalidade deve significar autonomia para decidir e garantir a execução da decisão. Essa última condição pressupóe que os Estados participantes aceitaram previamente subordinar suas vontades individuais às decisóes tomadas coletivamente pela instância regional, o que lhes garante a legitimação como instância responsável por determinadas decisóes.

A parcial cessão de autonomia sustenta-se pelo compromisso mútuo de submissão às decisóes dessa estrutura regional que se comporta em conformidade com as regras previamente acordadas pelos participantes da integração, que por sua vez reconhecem que essa estratégia garante maior estabilidade ao processo porque o preserva, de certo modo, das dinâmicas políticas nacionais.

Essa percepção está em consonância com o conceito de integração política estabelecido por Haas (2004), porque só é possível a transferência de lealdades e

5. Diante do impasse na resolução da crise política na Venezuela, em 8 de agosto de 2017, Argentina, Brasil, Canadá, Chile, Colômbia, Costa Rica, Guatemala, Honduras, México, Panamá, Paraguai e Peru, com posterior adesão de Guiana e Santa Lúcia, criam o Grupo de Lima por meio da assinatura da Declaração de Lima, com o objetivo de organizar uma saída para a crise no país bolivariano. 
expectativas para um novo centro de poder quando de fato tal centro apresentar a capacidade de decidir algo de forma autônoma em relação aos Estados-membros. Isso não significa que somente a supranacionalidade leva à integração política, mas facilita esse processo porque garante os compromissos dos atores. No limite, a divergência é resolvida com a desistência, como ocorreu no caso do Reino Unido e o processo do Brexit.

Contudo, a experiência recente da Uniáo Europeia com a negociaçáo do processo de saída do Reino Unido reforça o pressuposto neofuncionalista de que desintegrar pode ser mais custoso do que continuar (Haas, 2004). Deixar de participar de um bloco ou desintegrá-lo envolve o desmonte de uma complexa institucionalidade (regras e organismos) que engloba distintos interesses e atores. Isso significa que quanto mais institucionalizado o processo e maior a interdependência econômica entre os membros, maior proporcionalmente é o constrangimento em deixar de participar.

Um bom exemplo desse argumento é o que ocorreu na Unasul, em seu desmonte em favor de processos como o Prosul. Embora existisse uma institucionalidade relativamente abrangente nesse arranjo institucional, podemos identificar dois aspectos que facilitariam a sua desestruturação. Primeiramente, havia certa informalidade nessa institucionalidade, no sentido de que seu funcionamento não implicava na necessidade de adaptaçóes jurídicas ou de regras nos países membros. Além disso, outro aspecto refere-se à participação - como a Unasul não envolvia acordos comerciais, tampouco afetava diretamente interesses econômicos de setores importantes ou de grupos sociais organizados.

Esse aspecto explica em parte a pouca mobilização quando os governos indicaram o interesse em abandonar a Unasul, especialmente porque a grande maioria dos projetos de infraestrutura implementados pelo Conselho Sul-Americano de Infraestrutura e Planejamento (Cosiplan) é promovida por apenas um ou dois países (Ribeiro, 2016), o que permite a sua continuidade, mesmo com o fim do bloco. No caso do Mercosul, contudo, indicaçôes de retrocessos muitas vezes geram mobilizaçóes de importantes setores produtivos, como o automobilístico, que é altamente beneficiado pela integração.

Outra característica encontrada na região, relativamente à condição de constante sobreposição e repetição de esforços regionais, é a tendência derivada da lógica do spill around (Schmitter, 1970), na qual ocorre um alargamento institucional sem a necessidade de aprofundamento dos processos regionais. O Mercosul é o melhor exemplo dessa tendência, tendo passado, nas últimas duas décadas, tanto por uma estratégia de alargamento de membros (incorporação da Venezuela, e pedidos de adesão de Bolívia e Equador) como de uma ampliação e complexificação de sua institucionalidade, sem que houvesse qualquer alteração em seu processo decisório. 
A estrutura decisória do Mercosul permanece concentrada no Conselho do Mercado Comum (CMC) eno Grupo MercadoComum(GMC), ambos compostos por representantes dos governos, dentro de uma lógica intergovernamental que cria uma forte dependência das vontades políticas presidenciais. Essa dependência se traduziu inúmeras vezes em conflitos e crises internas no bloco, pois ao longo de sua existência os governos mostraram propensão a desrespeitar ou ignorar as regras, de acordo com interesses internos. $\mathrm{O}$ atual contexto talvez seja o de maior radicalização desse problema, por conta da tensão existente entre os governos da Argentina e do Brasil, que praticamente paralisou o processo, com indicaçóes de ambas as partes de uma disposição em abandonar o bloco.

Não obstante o posicionamento que tenhamos em relação ao debate sobre a institucionalização de projetos regionais, o fato é que, na América do Sul, independentemente dos momentos de criaçáo ou dos interesses que guiam os processos, todos estáo fundamentados na lógica intergovernamental, com estruturas institucionais sem autonomia decisória. Em princípio, essa centralização, por parte dos governos nos executivos, permitiria, teoricamente, que essas diferentes iniciativas estejam articuladas entre si, garantindo uma complementaridade entre esses projetos. No entanto, os argumentos aqui apresentados acerca do contexto dos blocos regionais, tendem a apontar para a compreensão das sobreposiçóes regionais como elemento agravador das dificuldades estruturais existentes. De modo a viabilizar a análise, na próxima seçâo ilustraremos as características já descritas, a partir do estudo de complementaridades e sobreposiçóes entre os interesses de projetos da região, levando em consideração seus diferentes propósitos e momentos de criação.

\section{PROJETOS REGIONAIS: COMPLEMENTARIDADES E SOBREPOSIÇÕES}

Em trabalho anterior, buscamos analisar a institucionalizaçáo dos processos de regionalismo sul-americanos (Mariano e Ribeiro, 2016). Conforme afirmamos anteriormente, a investigação demonstrou similaridades na composição de projetos intergovernamentais, de baixa institucionalidade, que ocorrem independentemente do momento de criação desses blocos. As organizaçóes criadas apresentam, então, estruturas específicas que visam atender suas demandas internas, e, mesmo com a variedade de inspiraçóes, é possível encontrar algumas similaridades entre eles.

Considerando as sobreposições de afiliações entre esses blocos, a análise dessas similaridades demonstrou também uma repetição de atores institucionais e temáticas, que permite a exploração do argumento relativo à utilização da multiplicidade de blocos regionais como ferramenta de manobra dos governos nacionais. Por exemplo, até 2015 , antes da crise regional que paralisou a atuação de alguns projetos, apenas consideradas as reunióes ministeriais de Mercosul, Unasul e Comunidade de Estados Latino-Americanos e Caribenhos (Celac), projetos em que o Brasil atuava, verificou-se 
A Pluralidade Institucional como Ferramenta Política na América do Sul: sobreposiç̧̃̃es organizacionais e fragmentação regional

que cerca de $50 \%$ das temáticas setoriais se repetiam entre os blocos, constando em pelo menos dois blocos a cada vez, conforme demonstrado no quadro 1.

QUADRO 1

Temáticas de reuniões/conselhos ministeriais no Mercosul, Unasul e Celac (até 2015)

\begin{tabular}{|c|c|c|c|}
\hline Tema/reunião ministerial & Mercosul & Unasul & Celac \\
\hline Agricultura & $x$ & & $\begin{array}{c}\mathrm{X} \\
\text { (agricultura familiar) }\end{array}$ \\
\hline Ciência, tecnologia e inovação & $x$ & $x$ & $x$ \\
\hline Cultura & $x$ & $x$ & $x$ \\
\hline Defesa & & $x$ & \\
\hline Desenvolvimento social & $x$ & $x$ & $\begin{array}{c}\mathrm{X} \\
\text { (segurança alimentar e nutricional e } \\
\text { erradicação da fome e da pobreza) }\end{array}$ \\
\hline Economia e finanças/bancos centrais & $x$ & $x$ & $x$ \\
\hline Educação & $x$ & $x$ & $x$ \\
\hline Eleitoral & & $x$ & \\
\hline Esporte & $x$ & & \\
\hline Indústria & $x$ & & $\begin{array}{c}\mathrm{X} \\
\text { (desenvolvimento produtivo } \\
\text { e industrial) }\end{array}$ \\
\hline Infraestrutura & & $\begin{array}{c}\text { X } \\
\text { (infraestrutura e planejamento) }\end{array}$ & $\begin{array}{c}\text { X } \\
\text { (infraestrutura para integração física } \\
\text { do transporte, telecomunicações e } \\
\text { integração fronteiriça) }\end{array}$ \\
\hline Interior & $x$ & & \\
\hline Justiça & $x$ & $\begin{array}{c}\text { X } \\
\text { (segurança cidadã, justiça e } \\
\text { coordenação contra a delinquência } \\
\text { organizada transnacional) }\end{array}$ & \\
\hline Meio ambiente & $x$ & & $x$ \\
\hline Minas e energia & $x$ & $\begin{array}{c}\mathrm{X} \\
\text { (energia) }\end{array}$ & $\begin{array}{c}\mathrm{X} \\
\text { (energia) }\end{array}$ \\
\hline Mulheres & $x$ & & \\
\hline Povos indígenas & $x$ & & \\
\hline Prevenção e combate à corrupção & & & $x$ \\
\hline $\begin{array}{l}\text { Privacidade e segurança da informação } \\
\text { e infraestrutura tecnológica }\end{array}$ & $x$ & & \\
\hline Problema mundial das drogas & & $x$ & $x$ \\
\hline Saúde & $x$ & $x$ & \\
\hline $\begin{array}{l}\text { Situações internacionais de desastre } \\
\text { humanitário }\end{array}$ & & & $x$ \\
\hline Trabalho & $x$ & & $x$ \\
\hline Turismo & $x$ & & \\
\hline
\end{tabular}

Fonte: Ribeiro (2016). 
A escolha pela comparação das reunióes ministeriais como amostra para exemplificação das agendas regionais derivou do fato de que a presença ou ausência de uma reunião de alto nível na estrutura institucional de um bloco poderia indicar os objetivos e interesses do processo, considerado que a participação ministerial setorizada é importante para a configuração e definição da agenda regional de políticas setoriais, dada a qualificação dos funcionários que assessoram os chefes de Estado na tomada de decisóes (Ribeiro, 2016). No entanto, essa escolha propositalmente desconsiderou ainda outras instâncias organizacionais dos blocos para comparação, o que potencializaria os efeitos da multiplicidade institucional.

Se, por um lado, uma agenda regional bastante abrangente, como a apresentada no quadro 1, poderia favorecer a complementaridade entre os processos, o resultado é uma repetição que não necessariamente contribuiu para o fortalecimento dos blocos ao descentralizar esforços. Ao contrário, a multiplicidade pode ter se apresentado ainda como fator potencial de dificuldade para a institucionalização e concretização dos processos regionais. Diante de um cenário de mudança das orientaçóes políticas e ideológicas dos governos nacionais, como o ocorrido a partir da segunda década do século XXI, passam entáo a ter problemas para manter o projeto regional conjunto.

De fato, é a partir de um momento de ruptura da coesão entre os governos da regiáo que os efeitos da sobreposição sobre o aprofundamento das instâncias regionais puderam evidenciar suas limitaçôes. Um bom exemplo é a compreensão de que, apesar da agenda abrangente da Unasul, com a crise política vigente na Venezuela desde a morte do ex-presidente Hugo Chávez, que dividiu os posicionamentos dos países vizinhos e sócios, ficaram expostas as fragilidades institucionais do bloco. Sem a capacidade de atuar autonomamente na ausência de um consenso, derivado de uma baixa institucionalidade, a iniciativa se viu fragmentada entre os países que apoiavam o governo bolivariano e os que o rejeitavam e finalmente se uniram em novos projetos: primeiramente o mencionado Grupo de Lima; posteriormente, o rearranjo dos países dissidentes da Unasul na conformação do Prosul.

Um ponto de convergência que pode ser apontado entre as diferentes experiências da região é a busca pelo desenvolvimento. Independentemente do processo histórico que lhe deu origem e da formação institucional resultante, podemos afirmar que a questão do desenvolvimento permanece como o grande motor dos referidos processos. No entanto, houve, ao longo do tempo, uma perceptível mudança no padrão de desenvolvimento buscado pelos países: na origem do Mercosul está a questão da superação do modelo do nacional-desenvolvimentismo promovido pelo Estado e a construção de um novo modelo associado a um crescimento econômico e comercial, gerando mecanismos 
liberais. Na primeira década do século XXI, ganhou força outra perspectiva, crescendo a percepção da necessidade de um desenvolvimento integrado aos aspectos sociais que levou à criação de instituiçôes com novas orientaçôes e maior intervenção estatal. Mais recentemente, há um crescente questionamento dessa perspectiva e a retomada do modelo anterior.

Essas mudanças de concepção sobre como promover o desenvolvimento e quais devem ser suas características refletem-se também sobre o modelo de integração defendido pelos governos. Muitas vezes há um descompasso entre o que os governos buscam e os instrumentos institucionais disponíveis, especialmente no caso do regionalismo. A mudança de percepção sobre como o desenvolvimento pode ser alcançado gera interesses conflituosos: as estruturas existentes atenderiam a interesses anteriores, exigindo a construçáo de novos mecanismos ou a reformulação de antigos.

É importante ressaltar que ditos interesses anteriores não são superados por completo, o que justifica a manutenção das instituiçóes existentes como instrumentos de continuidade de estratégias previamente adotadas. No entanto, nem sempre é possível incorporar nessas estruturas a nova agenda e interesses, pois muitas vezes isso implica ajustes e redefiniçóes, sendo mais simples criar novas instituiçóes. Além disso, o lançamento de novas iniciativas traz uma aura de novidade e de diferenciação ao novo governo, permitindo imprimir sua marca.

Essa dinâmica aparentemente complementar e positiva para os países e seus atores, ao permitir a utilização articulada de diferentes mecanismos regionais na consecução de seus objetivos e interesses, pode, no entanto, gerar um efeito contrário especialmente nos processos mais antigos que podem se esvaziar ou estagnar diante desse cenário de proliferação institucional. Explica-se: o Mercosul, como mecanismo mais antigo, e mais institucionalizado entre aqueles de que o Brasil participa, poderia perder relevância como espaço de discussão de uma temática na regiáo devido a sua menor abrangência de países e ao maior número de amarras apresentadas pela sua institucionalidade. Ainda que náo a favor da Unasul ou da Celac, tal perspectiva se confirma diante do crescente discurso por parte dos Estados-membros do Mercosul em defesa de novas formas de negociar, sem os constrangimentos do bloco.

Essa mesma tendência é encontrada na CAN. Sendo o processo de integraçáo mais antigo da América do Sul e o mais institucionalizado, no que se refere a órgãos com autonomia e certa supranacionalidade, é também o bloco mais desgastado. Desde os anos 1990, quando passou por uma renovaçáo pela qual os governos pretendiam dar um novo impulso a esse processo de integraçáo regional, a CAN está paulatinamente perdendo importância e visibilidade. 
Embora se identifique a saída da Venezuela em 2005 como elemento detonador de sua crise, o fato é que, após cinquenta anos de existência, a CAN nunca conseguiu promover seu objetivo inicial, que era aumentar a interdependência econômica entre seus integrantes e promover o desenvolvimento desses países. Além disso, mostrou-se ineficaz para dar respostas aos problemas estruturais das sociedades envolvidas (pobreza, desigualdade, democratização, violência etc.).

Isso explica em parte o entusiasmo que a criação da Aliança Bolivariana para os Povos da Nossa América - Tratado de Comércio dos Povos (ALBA-TCP) e da Aliança do Pacífico gerou em seus integrantes, levando a uma divisão clara entre os bolivarianos (Bolívia e Equador) e os liberais (Colômbia e Peru), que participaram respectivamente desses dois blocos alternativos. Com isso, houve um esvaziamento significativo da CAN dentro da política externa desses governos.

De um lado, a CAN não respondia à nova agenda dos governos chamados bolivarianos, que buscavam por meio da integraçáo regional promover um novo papel para o Estado, dentro do movimento que ficou conhecido como regionalismo pós-hegemônico ou pós-liberal, com uma agenda política marcada pela questão da autonomia e superaçâo dos problemas estruturais regionais, especialmente o da pobreza e desigualdade social.

Para os governosidentificados com esse alinhamento, projetos integracionistas como ALBA-TCP e Unasul faziam muito mais sentido como eixo da política externa do que a proposta da CAN construída em um contexto que defendia uma integração protecionista e que não conseguiu se adequar plenamente ao modelo do regionalismo aberto (Cepal, 1994).

Aliás, a incapacidade de promover plenamente o regionalismo aberto explica também o desinteresse de Peru e Colômbia, que ideologicamente não se alinhavam com os demais governos da Onda Rosa - com exceção do período da presidência de Alejandro Toledo no Peru -, embora participassem do processo da Unasul. A cooperação com a regiâo foi importante na política externa desses países durante os primeiros quinze anos do século XXI, mas o seu objetivo central não estava na região, e sim na Ásia.

A promoção da Aliança do Pacífico, que congrega Chile, Colômbia, México e Peru, é o melhor exemplo dessa reaçáo à Onda Rosa. Com um posicionamento claramente favorável ao liberalismo comercial e econômico, sua proposta se contrapóe às dos demais processos de integração da América do Sul. Isso se explica porque seu objetivo central é a inserção desses países nas cadeias internacionais de valor - com foco na Ásia, principalmente -, não a promoção de uma maior interdependência política ou econômica. 
É importante apontar que, conforme vão ocorrendo mudanças políticas nos países da América do Sul, caminhando para posicionamentos mais à direita no espectro político, a proposta da Unasul foi perdendo força ante o modelo mais aberto da Aliança do Pacífico. Esse fenômeno é visível inclusive em processos mais consolidados como o do Mercosul, no qual os governos passam a apontar a necessidade de se realizar revisóes nas regras de funcionamento para facilitar sua "flexibilização" para a promoção de acordos comerciais, e assim tornar o bloco mais dinâmico e inserido no comércio internacional. A crise de legitimidade das instituiçôes regionais parece confirmar as sobreposiçôes e a multiplicidade de projetos como instrumentos dos governos da regiáo, que se aproveitam da estratégia para mudar o foro quando é conveniente, ou até mesmo se posicionar de maneira elaboradamente inconsistente nos diversos projetos, dificultando seu aprofundamento institucional, e eventuais constrangimentos, como apontava Gómez-Mera na discussão teórica.

Assim, pode-se afirmar que as diversas instituiçôes, aliadas à flexibilidade de escolha institucional por parte dos Estados, ou a sua possibilidade de se envolver com processos regionais de seu interesse específico, têm criado na regiáo o que já foi analisado no caso europeu como o mencionado "regionalismo d̀ la carte" (Hofmann e Mérand, 2012) - cada Estado adota as instituiçóes que mais the convém. Só que, no caso sul-americano, a oportunidade de escolha, em vez de fortalecer os projetos, parece enfraquecê-los, ao diminuir ainda mais o comprometimento.

\section{CONSIDERAÇÕES FINAIS}

Consideradas as diferentes perspectivas teóricas apresentadas pela literatura especializada, e a evoluçâo do movimento de regionalismo na América do Sul, pode-se perceber que a ausência de conflito direto entre as instituiçóes, ao passo que poderia ter sido uma abertura para a atividade sinérgica e cooperativa, não necessariamente representou um efeito positivo, diante das dificuldades que os projetos regionais apresentaram na execução de seus objetivos e da forma como os países decidem negociar entre si. Mais do que isso, a possibilidade de criar novos projetos concretizou as hipóteses propostas de forum shopping, percebidas a partir da criação e dissolução de projetos segundo a conveniência, como observado na segunda década do século XXI com a queda da Unasul e a criação do Prosul, e, finalmente, o rompimento com a coesão regional. Assim sendo, resta refletir acerca das motivações da proliferação institucional e da continuidade das sobreposiçôes e seus significados na política dos países latino-americanos.

As reflexóes apresentadas neste trabalho denotam que a arquitetura regional da América do Sul e sua multiplicidade de projetos refletem a pluralidade de 
visões presentes acerca de como o desenvolvimento pode ser alcançado, quais são as ferramentas disponíveis para buscá-lo, quais os tipos de constrangimentos a que os Estados estáo dispostos a se submeter pelo sucesso do processo, quais as percepções compartilhadas de ameaças e segurança, quais as áreas prioritárias de negociaçáo, entre muitos outros fatores.

Além disso, neste trabalho, buscamos reunir os posicionamentos da literatura especializada a respeito das consequências que podem se desenvolver na região a partir da multiplicidade de processos. Diante de distintas possibilidades de competição e conflito entre os diferentes blocos regionais, um elemento a ser destacado para a articulação de interesses seria a presença de um ente conciliador, que assumisse a responsabilidade de concatenar as complementaridades dos distintos foros sub-regionais. Quer seja na figura de uma instituição regional mais abrangente, como propóe Nolte (2014), quer seja na condição de um paymaster como propóe Mattli (1999), fato é que não existe atualmente na América do Sul quem assuma esse papel. Isso demandaria maior esforço por parte dos governos para alcançar uma governança regional cooperativa, o que, de certa forma, também pode ser entendido como uma explicaçáo para a continuidade de sobreposiçóes ou a crescente desestruturação do regionalismo na regiáo.

Não podemos esquecer que uma característica atual dos sistemas políticos é o imediatismo, isto é, as açóes voltadas para a soluçấo de questóes de curto prazo. Essa realidade impacta diretamente as estratégias de regionalismo que acabam privilegiando a constituição de instituiçóes como resposta para crises sistêmicas e desafios momentâneos, e não para a construção de um projeto regional de longo prazo, ou a preocupaçáo com a conformação de um sistema de governança.

Olhando para o caso do Mercosul, por exemplo, percebemos que ao longo de sua existência esse projeto foi sendo redirecionado e redefinido, buscando ajustá-lo às mudanças contextuais - tanto domésticas como internacionais -, abandonando-se a preocupação em definir claramente seus objetivos e limites. Ao mesmo tempo, como apontamos anteriormente, nem sempre foi capaz de incorporar os novos interesses e agendas. Isso estimulou a criação de outras estruturas regionais para tratar de aspectos que não caberiam na lógica de integração desse processo, resultando em novas iniciativas regionais como a Unasul, a Celac e até mesmo o mais recente Prosul.

Reitera-se que todos esses processos ressaltaram a vontade de ampliar e aprofundar a integraçáo como instrumento para a promoção do desenvolvimento, seja a partir de uma plataforma centrada nos aspectos comerciais, como no Mercosul, seja envolvendo prioritariamente aspectos de infraestrutura e sociais, como no caso da Unasul. Portanto, podemos afirmar que a cooperaçáo faz parte 
de uma estratégia governamental mais ampla, mas não necessariamente de integração regional.

A ideia de Malamud e Gardini (2012) de que nem sempre a sobreposiçáo leva a um regionalismo competitivo, mas o segmenta, também leva à reflexão acerca do efeito simbólico da multiplicidade institucional. Dessa forma, faz-se importante compreender o que as sobreposições representam na articulação entre os países e para o relacionamento entre os vizinhos, e os significados que podem assumir na dificuldade em coordenar atividades e interesses, em ceder autonomia. Assim, gera-se um efeito psicológico negativo, de uma política regional autointeressada.

Retomando o debate teórico apresentado na primeira seção deste artigo, podemos afirmar que, ao longo do tempo, não houve na América do Sul uma vontade política para a construção de um projeto conjunto de desenvolvimento capaz de canalizar ou articular as expectativas dos países envolvidos. Dessa forma, a multiplicidade de iniciativas foi a estratégia usada para acomodar os distintos objetivos, resultando numa lógica de desarticulação na construção de uma convergência de interesses.

Como não há um projeto coletivo que articule os interesses, tampouco há um compromisso com a constituiçâo de uma nova institucionalidade para gerir a cooperação. Para além disso, os instrumentos criados permanecem condicionados às vontades políticas dos governos e são acionados ou descartados, de acordo com os contextos e lógicas de curto prazo.

Ou seja, um aspecto que fica evidente no caso latino-americano é justamente que há uma preocupação em compatibilizar os regionalismos com a manutenção das soberanias nacionais, o que na prática significou uma intensificação das lógicas intergovernamentais. Os Estados permanecem como o centro do poder decisório, mas as mudanças governamentais características dos regimes democráticos provocam constantes redirecionamentos nas estratégias regionais e na relevância dada aos distintos processos. A proliferação de iniciativas fundamenta-se, portanto, numa lógica alheia à construçáo de um projeto regional articulado, prevalecendo a prática de construção de novos processos não para complementar, mas para superar os existentes.

Temos entâo como característica central do regionalismo sul-americano a falta de disposição para o aprofundamento e a ampliação da agenda de negociação, marcada pela resistência dos governos em ceder algum tipo de autonomia para as instâncias regionais. Essa constatação tem como consequência duas tendências: de baixo comprometimento e de alto descumprimento das normas, ou de sua flexibilização. 
Diante desse cenário, as expectativas dos atores sobre os benefícios do regionalismo tendem a ser muito restritas ou mesmo negativas. A cooperação regional não é suficientemente atrativa para compensar os custos de participar, explicando a atual conjuntura da América do Sul. A Celac está praticamente abandonada porque não se consegue identificar claramente as vantagens nesse processo. No caso da Unasul, sua desvinculação com a agenda política dos atuais governos e seu baixo enraizamento nos ordenamentos jurídicos nacionais permitiram a opção pelo desmonte. Já o Mercosul sofre um processo de reconfiguração, agravado pela ruptura nas relaçóes entre seus principais parceiros Argentina e Brasil -, intensificando a tendência de desestruturação do bloco.

Os demais processos existentes na região não se encontram em melhor situação, estando também estagnados ou se desestruturando. Mesmo a iniciativa do Prosul, para a criação de uma nova articulação regional, mostrou-se incapaz de reverter essa tendência desarticuladora, inclusive na sua fraca intenção de tentar coordenar uma resposta regional à pandemia da Covid-19 que assola o mundo em 2020. Na verdade, diante de uma situação excepcional e de crise, é interessante perceber como a institucionalidade dos processos regionais se mostra relevante: frente a uma maior demanda, os processos com maiores constrangimentos têm maior capacidade de atuação independente dos executivos nacionais, possibilitando açóes, como a destinação de um fundo de emergência de US\$ 16 milhóes por parte do Fundo de Convergência Estrutural do Mercosul (FOCEM) para o combate ao novo coronavírus (Mercosul, 2020), em contraposição às açôes limitadas de iniciativas regionais contemporâneas como o Prosul (Verdélio, 2020).

Por fim, reiteram-se os efeitos que uma grande quantidade de blocos regionais impóe à institucionalidade de ditos processos: só é possível que os países participem de várias iniciativas simultaneamente porque impóem poucos constrangimentos, o que, por sua vez, abre a possibilidade para a escolha do projeto que convém aos interesses dos governos. E, quando determinado bloco não atende ao interesse dos países envolvidos, torna-se simples criar novos projetos que contribuam ainda mais para a complexidade organizacional da região.

Portanto, o problema causado pela proliferação institucional e o overlapping na América do Sul náo é unicamente saber se promovem cooperação ou competição, como discutia a literatura durante a efervescência da primeira década do século XXI, mas o tipo de expectativas que são geradas nos atores em relação à integração regional, pois interferem nos comportamentos e no grau de comprometimento com a cooperação, principalmente a longo prazo. Como resultado, na América do Sul, a possibilidade de escolher o projeto que mais convém faz da multiplicidade uma ferramenta para as políticas nacionais que traz descrença nas vantagens dos processos de integração. 


\section{REFERÊNCIAS}

AYERBE, L. F. Novos atores políticos e alternativas de governo: os casos de Argentina, Bolívia, Brasil e Venezuela. In: . (Org.). Novas lideranças políticas e alternativas de governo na América do Sul. São Paulo: Editora Unesp, 2008. p. 265-301.

BÖRZEL, T. A.; RISSE, T. (Ed.). The Oxford handbook of comparative regionalism. New York: Oxford University Press, 2016.

BRICEÑO-RUIZ, J.; PUNTIGLIANO, A. R. Brazil and Latin America: between the separation and integration paths. Lanham: Lexington Books, 2017.

CEPAL-COMISIÓN ECONÓMICA PARA AMÉRICALATINA E EL CARIBE. El regionalismo abierto en América Latina y el Caribe: la integración económica al servicio de la transformación productiva con equidad. Santiago: Cepal, 1994.

CIENFUEGOS, M.; SANAHUJA, J. A. (Ed.). Una región en construcción: Unasur y la integración en América del Sur. Barcelona: Cidob, 2010.

GÓMEZ-MERA, L. International regime complexity and regional governance: evidence from the Americas. Global Governance, v. 21, n. 1, p. 19-42, 2015.

HAAS, E. B. The uniting of Europe: political, social, and economic forces, 1950-1957. Indiana: University of Notre Dame Press, 2004.

HOFMANN, S. C.; MÉRAND, F. Regional organizations à la carte: the effects of institutional elasticity. In: PAUL, T. V. (Ed.). International relations theory and regional transformation. New York: Cambridge University Press, 2012. p. $133-157$.

HURRELL, A. O ressurgimento do regionalismo na política mundial. Contexto Internacional, v. 17, n. 1, p. 23-59, jan./jun. 1995.

MALAMUD, A. Overlapping regionalism, no integration: conceptual issues and the Latin American experiences. Fiesole: EUI, 2013. (Working Paper, n. 2013/20). Disponível em: <http://cadmus.eui.eu/handle/1814/26336>.

MALAMUD, A.; GARDINI, G. L. Has regionalism peaked? The Latin American quagmire and its lessons. The International Spectator: Italian Journal of International Affairs, v. 47, n. 1, p. 116-133, 2012.

MARIANO, K. L. P. (Coord.). Regionalismo na América Latina no século XXI: relatório final da pesquisa. Araraquara: Editora Unesp, 2016.

MARIANO, K. L. P.; RIBEIRO, C. C. N. Regionalismo na América Latina no século XXI. In: SALATINI, R. (Org.). Cultura e direitos humanos nas relaçóes internacionais: reflexôes sobre cultura. 1. ed. São Paulo: Cultura Acadêmica, 2016. v. 1, p. 23-40. 
MARIANO, K. L. P.; ROMERO, A. M. S.; RIBEIRO, C. C. N. Percepçóes governamentais sobre a integração regional na América do Sul. Boletim de Economia e Política Internacional, v. 21, p. 33-43, set./dez. 2015.

MATTLI, W. The logic of regional integration: Europe and beyond. New York: Cambridge University Press, 1999.

MERCOSUL - MERCADO COMUM DO SUL. Esforço regional contra a pandemia: o Mercosul aprovou um fundo de emergência de US\$ 16 milhóes que será destinado totalmente para o combate contra a COVID-19. Mercosul, 3 abr. 2020. Disponível em: <https://www.mercosur.int/pt-br/esforco-regional-contraa-pandemia-o-mercosul-aprovou-um-fundo-de-emergencia-de-us-16-milhoesque-serao-destinados-totalmente-para-o-combate-contra-o-covid-19/>.

MITRANY, D. A paz por meio da cooperaçáo e da integração. In: BRAILLARD, P. (Org.). Teoria das relaçóes internacionais. Lisboa: Fundação Calouste Gulbenkian, 1990.

The funcionalist alternative. In: WILLIAMS, P.; GOLDSTEIN, D. M.; SHAFRITZ, J. M. (Ed.). Classic readings of international relations. New York: Hartcourt Brace College, 1994.

NOLTE, D. Latin America's new regional architecture: a cooperative or segmented regional governance complex? Fiesole: EUI, 2014. (Working Paper, n. 2014/89). Disponível em: <http://cadmus.eui.eu/bitstream/ handle/1814/32595/RSCAS_2014_89.pdf?sequence=>.

Regional governance from a comparative perspective. In: GONZÁLEZ-SÁNCHEZ, V. M. (Ed.). Economy, politics and governance challenges for the 21st Century. New York: Nova Science, 2016.

. Costs and benefits of overlapping regional organizations in Latin America: the case of the OAS and Unasur. Latin American Politics and Society, v. 60, n. 1, p. 128-153, 2018.

RIBEIRO, C. C. N. Overlapping regionalism e proliferaçáo de instituiçóes na América Latina: complementaridade e fragmentação nas agendas regionais. 2016. Dissertação (Mestrado) - Universidade Estadual Paulista Júlio de Mesquita Filho, São Paulo, 2016. Disponível em: <http://repositorio.unesp.br/ handle/11449/136383>.

RIGGIROZZI, P.; TUSSIE, D. (Ed.). The rise of post-hegemonic regionalism: the case of Latin America. Dordrecht: Springer, 2012.

SCHMITTER, P. C. A revised theory of regional integration. International Organization, v. 24, n. 4, p. 836-868, 1970. 
SERBIN, A. Los nuevos escenarios de la regionalización: déficit democrático y participación de la sociedad civil en el marco del regionalismo suramericano. Bogotá: Cries, 2011. (Documentos Cries, n. 17).

TUSSIE, D. Latin America: contrasting motivations for regional projects. Review of International Studies, v. 35, n. S1, p. 169-188, 2009.

VEIGA, P. M.; RÍOS, S. O regionalismo pós-liberal na América do Sul: origens, iniciativas e dilemas. Santiago: CEPAL, 2007. (Série Comércio Internacional, n. 82).

O Brasil como vetor de integração sul-americana: possibilidades e limites. Política Externa, v. 20, n. 2, p. 73-94, 2011.

VERDÉliO, A. Países do Prosul adotam medidas conjuntas para enfrentar Covid-19. Agência Brasil, 17 mar. 2020. Disponível em: <https://agenciabrasil. ebc.com.br/politica/noticia/2020-03/paises-do-prosul-adotam-medidasconjuntas-para-enfrentar-covid-19>.

VIGEVANI, T.; RAMANZINI JÚNIOR, H. Autonomia e integração regional no contexto do Mercosul: uma análise considerando a posição do Brasil. Debates Clacso, n. 27, p. 46-65, 2010.

WEIFFEN, B. Institutional overlap and responses to political crises in South America. In: SUAREZ, M. A. G.; VILLA, R. D.; WEIFFEN, B. (Ed.). Power dynamics and regional security in Latin America. London: Palgrave Macmillan, 2017.

WEIFFEN, B.; WEHNER, L.; NOLTE, D. Overlapping regional security institutions in South America: the case of OAS and Unasur. International Area Studies Review, v. 16, n. 4, p. 370-389, 2013. 
